\title{
The Role of Interleukin-6 and Interleukin-8 Gene Polymorphisms in Non-Alcoholic Steatohepatitis
}

\author{
Mustafa Cengiz ${ }^{1, *}$; Demet Gokalp Yasar $^{2}$; Mehmet Ali Ergun ${ }^{3}$; Gulen Akyol ${ }^{4}$; Seren \\ Ozenirler $^{5}$ \\ ${ }^{1}$ Department of Gastroenterology, Ankara Oncology Training and Research Hospital, Ankara, Turkey \\ 2 Department of Internal Medicine, Faculty of Medicine, Gazi University, Ankara, Turkey \\ ${ }_{4}^{3}$ Department of Genetics, Faculty of Medicine, Gazi University, Ankara, Turkey \\ 4 (Department of Pathology, Faculty of Medicine, Gazi University, Ankara, Turkey \\ 5 Department of Pathology, Faculty of Medicine, Gazi University, Ankara, Turkey \\ ${ }^{*}$ Corresponding Author: Mustafa Cengiz, Department of Gastroenterology, Ankara Oncology Training and Research Hospital, 06200, Yenimahalle, Ankara, Turkey. Tel: +90- \\ 3123360909, Fax:+90-3123340352, E-mail: drmustafacen@gmail.com
}

Received: October 15, 2014; Revised: November 25, 2014; Accepted: December 7, 2014

\begin{abstract}
Background: Genetic polymorphisms may play role in the pathophysiology of nonalcoholic steatohepatitis (NASH).
Objectives:We purposed to assess the role of interleukin 6(IL 6) and interleukin 8(IL8) gene polymorphisms in the pathogenesis of NASH. Patients and Methods: Consecutive patients with biopsy proven NASH and age- and gender-matched healthy individuals with normal liver function tests and normal ultrasonography were enrolled in the study. Histopathological findings were recorded according to nonalcoholic fatty liver disease activity score (NAS). Patients were classified according to fibrosis scores as fibrosis score $<2$ (mild fibrosis group) and fibrosis score $\geq 2$ (significant fibrosis group). Blood samples were collected and genomic DNA isolation kit was used to evaluate genetic polymorphisms.

Results: Of thirty-eight patients, 27 (71\%) were in mild fibrosis group and 11(29\%) in significant fibrosis group. Thirty-eight age- and gendermatched healthy controls were enrolled in the study. The frequencies of genotypes G/C and G/G of IL 6 among the NASH group and healthy controls were $39.5 \%$ and $60.5 \%$ vs. $53.6 \%$ and $46.4 \%$, respectively $(\mathrm{P}=0.32$. The frequencies of the genotypes of IL 8 among the NASH group were $47.2 \%, 44.6 \%$, and $8.2 \%$ for T/T, A/T, and A/A, and in healthy controls were $50 \%, 28.6 \%$ and $21.4 \%$, respectively, $(\mathrm{P}=0.568)$. The differences between IL 8 gene T/A and T/T genotypes were not significant statistically $(\mathrm{P}>0.05)$. However, the frequency of A/A genotype in significant fibrosis group was higher than the mild fibrosis group $(\mathrm{P}=0.0016)$. The differences of $-251 \mathrm{~A} / \mathrm{T}$ polymorphism in the IL 8 and $-174 \mathrm{C} / \mathrm{G}$ polymorphism in the IL 6 were not statistically significant between fibrosis groups $(\mathrm{P}>0.05)$.

Conclusions: IL6 and IL8 gene polymorphisms have no role in NASH pathogenesis and liver fibrosis process, but presence of the A/A genotype in the IL8 gene is associated with disease progression.
\end{abstract}

Keywords:Genetics; Fibrosis; Polymorphism, Genetic

\section{Background}

Nonalcoholic steatohepatitis (NASH) has been shown to be associated with obesity, diabetes and hyperlipidemia (1). The disease pathophysiology is not fully clear and seems to be multifactorial. Current models propose the "two hit hypothesis". First, lipids accumulate in hepatocytes and then trigger inflammation by a variety of mechanisms (2). Insulin resistance, lipid peroxidation, oxidative stress, endotoxins and cytokines are possible mechanisms in the pathogenesis of NASH. In addition, some genetic backgrounds may have considerable effects on the clinical course and prognosis of disease (3).

Interleukin 8 (IL8), a family member of the chemokine, has a role in induction and amplification of inflammatory processes (4). Increased plasma IL 8 levels were detected in NASH patients (5-7). Therefore, it may have a crucial role in NASH disease in which inflammation is a substantial pathophysiological feature. The (-251 A/T) polymorphism in IL 8 gene's promoter region is the only one influencing gene expression (8).

Interleukin 6 (IL 6), as a cytokine, has pleiotropic features, takes part in regulation, proliferation, differentiation and various activities of cell types. It also has an important part in neuro-endocrine and homeostasis of immune system (9). Dysregulated IL 6 production is implicated in the pathology of several disease processes such as multiple myeloma, arthritis, diabetes, atherosclerosis and hepatocellular carcinoma (HCC) in patients with chronic hepatitis B (10-13). In 5' upstream of IL 6 (-174 C/G locus) a localization of $C / G$ polymorphism has been shown (14). This basic modulation has been correlated to various IL 6 plasma values and proportion of IL 6 gene transcription in healthy subjects (10). Furthermore, increased plasma IL 6 levels were found in patients with NASH in a pilot study (6). Increasing scientific facts indicate that interracial differences and

Copyright ( 2014, Kowsar Corp. This is an open-access article distributed under the terms of the Creative Commons Attribution-NonCommercial 4.0 International License (http://creativecommons.org/licenses/by-nc/4.0/) which permits copy and redistribute the material just in noncommercial usages, provided the original work is properly cited. 
genetic factors have an impact on the natural history of chronic liver disorders. It has been concluded that gene polymorphisms affect the advancement of liver fibrosis among patients infected with hepatitis $\mathrm{C}$ virus (HCV), autoimmune chronic cholestasis and autoimmune liver diseases (15). The roles of genetic factors in NASH have been estimated in several studies $(10,11,16)$. Several candidate genes relevant to the "second hit hypothesis" have been preliminarily examined. A polymorphism in manganese superoxide dismutase (MnSOD), a gene limiting mitochondrial oxidative stress, was reported to be enriched as a cohort in patients with NASH (17). Polymorphisms in two genes, angiotensinogen and transforming growth factor- $\beta 1$, have been associated with greater fibrosis in morbidly obese subjects undergoing bariatric surgery (18). A Japanese study revealed that polymorphisms of Interleukin 1-beta and beta-3 adrenergic receptors affect the development of NASH (19).

\section{Objectives}

We aimed to investigate whether IL 6 and IL 8 gene polymorphisms play role in identification and pathophysiology of NASH and to evaluate the roles of the promoter (-174 G/C) of IL 6 and promoter (-251 A/T) of IL 8 polymorphisms.

\section{Patients and Methods}

\subsection{Patients}

Consecutive participants with biopsy proven NASH who had persistently elevated liver enzymes and hepatosteatosis on ultrasonography, in the absence of any causes of elevated aminotransferase levels, such as viral hepatitis, sclerosing cholangitis, autoimmune hepatitis, primary biliary cirrhosis, Wilson's disease, hemochromatosis, alpha- 1-antitrypsin deficiency, malignancy and drug-induced liver disease were enrolled in the study. Excessive alcohol consumption of ( $>20 \mathrm{~g} /$ day) was also considered as exclusion criteria. The healthy control group included consecutive age- and gender-matched individuals who had normal aminotransferase levels and normal abdominal ultrasonography and without any illness, alcohol consumption, drug or herbal substance usage, history of previous liver diseases and with negative results for viral hepatitis markers.

Demographic and clinical data of patients were collected and registered in a database by the same clinician to prevent bias. Anthropometric measurements, including height, body weight and body mass index (BMI), were recorded. BMI was calculated as weight (in kilograms) divided by the square of height (in meters) as $\mathrm{kg} / \mathrm{m}^{2}$ in all patients and controls.

\subsection{Evaluation of IL Genotyping}

Blood samples were taken in bottles containing 72 $\mu \mathrm{L} 7.5 \%$ concentrations of K3-EDTA (BD, USA). For DNA isolation, $200 \mu \mathrm{L}$ of blood from the samples was used and purificated by EZ-DNA Genomic DNA Isolation Kit (Biological Industries, Israel). Polymerase chain reactions (PCRs) were performed with appropriate primers after genomic DNA was obtained from the peripheral blood of patients and control subjects. For determination of IL 6 gene $-174 \mathrm{G} / \mathrm{C}$ (rs1800795), and IL8 -251 A/T (rs4073) polymorphisms, F-5'-TTCGTGCATGACTTCAGCTTTAC-3' R-5-'AGCCTCAGACATCTCCAGTCCT-3' and F-5-'CCATCATGATAGCATCTGTA-3' R-5'-CCACAATTTGGTGAATTATTA-3' primers were selected, respectively. Both PCR reactions consisted of $16 \mathrm{mM}(\mathrm{NH} 4) 2 \mathrm{SO} 4,67 \mathrm{Mm}$, TrisHCL pH 8.8, 0.01\%Tween-20, $1.5 \mathrm{Mm} \mathrm{MgCI}_{2}, 200 \mu \mathrm{M}$ for each deoxynucleotide triphosphate, $0.026 \mathrm{U} / \mu \mathrm{L}$ TaqDNA polymerase enzyme (Bioron, Germany) and nearly 0.5 $\mu \mathrm{g}$ mold of DNA was put in each tube. PCR conditions regarding both of the polymorphisms were performed as follows: denaturation at $94^{\circ} \mathrm{C}$ for five minutes, followed by 30 cycles of denaturation at $94^{\circ} \mathrm{C}$ for 30 seconds, annealing at $60^{\circ} \mathrm{C}$ for 30 seconds and extension at $72^{\circ} \mathrm{C}$ for 30 seconds, with a final extension at $72^{\circ} \mathrm{C}$ for five minutes. We used a control without DNA to check for contamination. Two percent agarose gel revealed a PCR product of 330-bp for the -174G/C polymorphism and a 174-bp for IL 8 $-251 \mathrm{~A} / \mathrm{T}$ polymorphism.

To genotype -174G/C polymorphism, a 330 bp PCR product was digested with 10 units of SfaNI restriction enzyme at $37^{\circ} \mathrm{C}$ for overnight. The results were evaluated with two blind observers after electrophoresed in a 3\% agarose gel. The presence of restriction sites on both alleles was digested in fragments of 182 and 148 bp were labeled as GG genotype; whereas, the absence of restriction sites, gave one $330 \mathrm{bp}$ fragment revealed as CC genotype.

Regarding the genotype pf -251 A/T polymorphism of IL 8 gene, a $174 \mathrm{bp}$ PCR product was digested with 10 units of AseI restriction enzyme at $37^{\circ} \mathrm{C}$ for overnight. The results were evaluated with two blind observers after electrophoresed in a 3\% agarose gel. The presence of restriction sites on both alleles was digested in fragments of 152 and 22 bp were labeled as AA genotype; whereas, the absence of restriction sites, gave one $174 \mathrm{bp}$ fragment revealed as TT genotype.

\subsection{Liver Histopathological Evaluation}

Percutaneous liver biopsy was performed using a 16-G disposable needle by a skilled clinician. All liver biopsy specimens included 10-12 or more complete portal tracts and were at least $20-25 \mathrm{~mm}$ in length assessed by an experienced hepatopathologist blinded to clinics and anthropometric data of patients. Tissue specimens were fixed in formalin, embedded in paraffin and prepared with Hematoxylin/Eosin and Masson's trichrome stains to assess the morphology and fibrosis of the liver.

Diagnosis of NASH was made according to the Brunt's Criteria (20). Histological features were graded in accordance with the NAFLD scoring system (NAS) and the 
National Institute of Diabetes and Digestive and Kidney Diseases NASH Clinical Research Network (21). Hepatic steatosis was according to steatosis percentage; 5-33\%, $33-66 \%$ and $>66 \%$ denoting scores 1, 2 and 3, respectively. Lobular inflammation was identified as the entire assessment of all inflammations; no foci as score $0,<2$ foci per x200 field as score 1, two-four foci per x200 field as score $2,>4$ foci per $x 200$ field as score 3 . Ballooning scoring was termed as; score 0 no ballooning; score 1 as few and score 2 existence of numerous ballooning of hepatocytes. Liver fibrosis was staged as follows; stage 0 , no fibrosis; stage 1 , perisinusoidal or periportal fibrosis; stage 2, perisinusoidal and portal/periportal fibrosis; stage 3, bridging fibrosis and stage 4 as cirrhosis. Histopathologically, total NAS was calculated as a sum of steatosis (1-3), lobular inflammation (0-3) and ballooning (0-2). NAS $\geq 5$ was identified as definite NASH and all patients were diagnosed as definite NASH. Patients were classified as mild and significant fibrosis groups. While, mild fibrosis group was characterized as fibrosis score $<2$ pathologically represented in Figure $1 \mathrm{~A}$ and significant fibrosis group was characterized as fibrosis score $\geq 2$ shown in Figure 1 B (22).

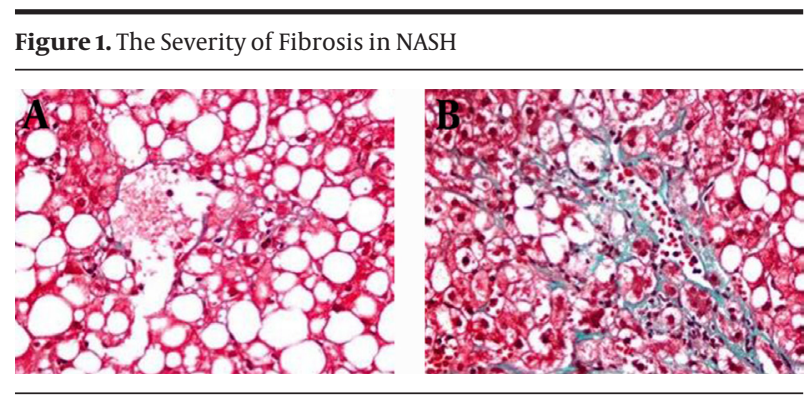

A) Mild fibrosis due to NASH; B) Significant fibrosis due to NASH.

\subsection{Ethics}

This study was performed according to the ethical guidelines of the 1975 Declaration of Helsinki, as updated in 2008. The local ethics committee of Gazi University School of Medicine approved the research protocol by the number of 244.2006.16.6. Informed and signed consents were obtained from all patients and healthy controls.

\subsection{Statistical Analysis}

Statistical analysis was performed using SPSS version 21 (Statistical Package for Social Science; Chicago, IL, USA). The variables were investigated using visual (histograms, probability plots) and analytical methods (KolmogorovSmirnov/Shapiro-Wilk's test) to determine whether they were normally distributed. Descriptive analysis was presented as frequencies for ordinal variables and as mean \pm standard deviation for normally distributed continuous variables. The comparisons of non-normally distributed continuous variables were performed using Mann-Whitney U test. Chi-square test or Fisher's exact test, where appropriate, was used to compare the groups. The compari- son of normally distributed continuous variables was performed using Student t-test. The comparisons of multiple groups were made by Kruskal-Wallis test and Bonferroni correction was performed where appropriate. $\mathrm{P}$ $<0.05$ was noted statistically significant for all analyses.

\section{Results}

Thirty-eight consecutive patients with biopsy proven NASH and 38 age- and gender-matched voluntary healthy controls were recruited in the study compatible with inclusion and exclusion criteria. Age and gender of groups were comparable with each other. NASH patients had higher BMI than healthy controls $929.3 \pm 2.3$ vs. $27.8 \pm 2.1$, $\mathrm{P}=0.007)$. The main baseline characteristics of patients and healthy controls are shown in Table 1.

The comparisons of frequencies of the two genotypes G/C and G/G of IL 6 between NASH group and healthy controls were $39.5 \%$, 60.5\% vs. 53.6\%, 46.4\%, respectively, but there was no statistically significant differences between the two groups $(\mathrm{P}>0.05)$. The frequencies of genotypes of IL 8 among NASH group were $47.2 \%, 44.6 \%$ and $8.2 \%$ for $\mathrm{T} / \mathrm{T}, \mathrm{A} / \mathrm{T}$, and A/A, while among healthy controls were $50 \%$, $28.6 \%$ and $21.4 \%$, respectively, $(P>0.05)$. The frequencies of distribution of IL 6 and IL 8 gene polymorphisms between patients with NASH and healthy controls are shown in Table 2. Liver biopsy samples were consistent with histopathological diagnosis of NASH and NAS scores were $\geq$ 5 in all patients. According to fibrosis scores there were $27 / 38$ (71\%) patients in mild fibrosis group, while there were 11/38 (29\%) in significant fibrosis group. From all patients, 4 (10.5\%) were in F0, 23 (60.5\%) in F1, 6 (15.8\%) in F2, $4(10.5 \%)$ in F3 and 1 (2.7\%) in F4.

To further investigate the role of genetic polymorphisms and genotypes between fibrosis groups we compared the frequencies of $-174 \mathrm{C} / \mathrm{G}$ polymorphism in the IL 6 gene, -251 A/T polymorphism of IL 8, G/G and G/C genotypes of IL6 between the groups, but there was no statistically significant difference $(P>0.05)$. However, the A/A genotype was significantly higher in patients of significant fibrosis group than the mild fibrosis group $(27.3 \%$ vs. $0 \%)$, respectively and $(\mathrm{P}=0.0016)$. Comparing $\mathrm{T} / \mathrm{T}, \mathrm{T} / \mathrm{A}$ and A/A genotypes of IL 8 gene between fibrosis groups is shown in Table 3.

Table 1. Baseline Characteristics of Patients With NASH and Healthy Controls ${ }^{\text {a,b }}$

\begin{tabular}{lccc}
\hline & $\begin{array}{c}\text { NASH } \\
\text { Patients } \\
(\mathbf{n}=\mathbf{3 8})\end{array}$ & $\begin{array}{c}\text { Healthy } \\
\text { Controls } \\
(\mathbf{n}=\mathbf{3 8})\end{array}$ & PValue \\
\hline Age, $\mathbf{y}$ & $45.5 \pm 10.2$ & $46.5 \pm 8.5$ & NS \\
Gender, Female/Male & $14 / 24$ & $14 / 24$ & NS \\
BMI, $\mathbf{~} / \mathbf{m}^{2}$ & $29.3 \pm 2.3$ & $27.8 \pm 2.1$ & 0.007 \\
\hline
\end{tabular}

a Abbreviations: BMI, body mass index; NASH, nonalcoholic steatohepatitis; NS, not significant.

$\mathrm{b}$ Data are expressed as mean \pm SD. 
Table 2. Comparing Frequencies of IL 6 and IL 8 Gene Polymorphisms Between NASH Patients and Healthy Controls ${ }^{\mathrm{a}, \mathrm{b}}$

\begin{tabular}{lccc}
\hline Genotypes & NASH Patients & Healthy Controls & P Value \\
\hline IL 6 & & & \\
\hline $\mathrm{G} / \mathrm{G}$ & $23(60.5)$ & $18(46.4)$ & $\mathrm{NS}$ \\
$\mathrm{G} / \mathrm{C}$ & $15(39.5)$ & $20(53.6)$ & $\mathrm{NS}$ \\
$\mathrm{IL} 8$ & & \\
$\mathrm{~T} / \mathrm{T}$ & $19(50)$ & $\mathrm{NS}$ \\
$\mathrm{T} / \mathrm{A}$ & $18(47.2)$ & $11(28.6)$ & $\mathrm{NS}$ \\
$\mathrm{A} / \mathrm{A}$ & $17(44.6)$ & $8(21.4)$ & $\mathrm{NS}$ \\
\hline $\begin{array}{l}\text { a Abbreviations: } \\
\text { significant. }\end{array}$ & NASH; non-alcoholic & steatohepatitis, & NS; not \\
bata are presented as No.(\%). & &
\end{tabular}

Table 3. Comparing IL 8 Genotypes Between Fibrosis Groups of $\mathrm{NASH}^{\mathrm{a}, \mathrm{b}}$

\begin{tabular}{lccc}
\hline IL 8 Genotypes & $\begin{array}{c}\text { Mild } \\
\text { Fibrosis }^{\mathrm{C}}(\mathbf{n}=\mathbf{2 7})\end{array}$ & $\begin{array}{c}\text { Significant } \\
\text { Fibrosis }^{\mathrm{d}}(\mathbf{n}=\mathbf{1 1})\end{array}$ & P Value \\
\hline T/T & $13(34.2)$ & $3(27.3)$ & NS \\
T/A & $14(36.1)$ & $5(45.4)$ & NS \\
A/A & $0(0)$ & $3(27.3)$ & 0.0016 \\
\hline a Abbreviations: & NASH; non-alcoholic & steatohepatitis, & NS; not \\
significant. & & \\
b Data are presented as No. (\%). & & \\
c Mild fibrosis: Fibrosis score <2. & & \\
d Significant fibrosis: Fibrosis score $\geq 2$. & &
\end{tabular}

\section{Discussion}

In this research, we investigated IL6 and IL8 gene polymorphisms in NASH patients and healthy controls and attempted to define their roles in the pathogenesis and severity of disease. Our results indicated that polymorphisms in IL 6 and IL 8 genes had no effect on the identification of NASH as there was no difference compared to healthy controls. However, the presence of A/A genotype of the IL 8 gene is associated with disease progression. Besides, polymorphisms of $-174 \mathrm{C} / \mathrm{G}$ polymorphism in the IL 6 gen and $-251 \mathrm{~A} / \mathrm{T}$ polymorphism of IL 8 had no roles in the progression of liver fibrosis. The poorly understood pathogenesis of NASH seems to be multifactorial (2). In this study, we confirmed higher BMIs NASH patients. In a Japanese study, it was concluded that obesity is a substantial variable in the progression of NASH (19).

While environmental risk factors clearly affect the emergence and development of NASH, the diversity of phenotypes in persons with similar metabolic risk factors strongly implies a genetic contribution (23). A useful and commonly held theory to explain the pathogenesis of NASH is the "two hit" hypothesis (2). The "first hit" is characterized by initiation of hepatic steatosis and the "second hit" is characterized by increased intracellular oxidative stress that can be induced by numerous mechanisms, including endotoxin exposure, pro-inflammatory cytokines (23). Proinflammatory cytokines, IL6 and IL8, have been thought to be involved in the pathogenesis of $\mathrm{NASH}$, but the underlying mechanisms have not been determined exactly yet (5-7). In this study, we investigated IL6 and IL8 gene polymorphisms in NASH patients and attempted to define their role in the pathogenesis and severity of disease. In our study, we assessed the role of IL 8 polymorphism in the "second hit" pathogenesis of NASH, but no statistically remarkable difference was seen between NASH patients and healthy individuals. Nevertheless, the A/A genotype was higher among patients with severe NAS. These observations support the idea that the A/A allele is profoundly involved in the NASH progression. IL8, a substantial cytokine, takes part in the inflammatory process. Bahcecioglu et al. found that serum IL8 values of NASH patients were higher than controls (5). Moreover, in another study IL8 was significantly higher in NASH patients than steatosis group (7). A study from China concluded that IL 8 may take part in the pathogenesis of NAFLD in Chinese patients and concluded that patients who had high ALT levels had higher IL 8 levels. Nevertheless, there was no difference among NASH patients (24). The $-251 \mathrm{~A} / \mathrm{T}$ polymorphism in the promoter zone of the IL 8 gene affects its expression. The mutant allele "A" of the $-251 \mathrm{~A} / \mathrm{T}$ polymorphism is less common, but its presence increases the production of IL 8 cytokine (8). A pilot study found that monocytes from NASH patients overproduced tumor necrosis factor (TNF), IL 6 and IL 8 and after lifestyle modification and vitamin E therapy, the levels of IL 8 remained elevated. This data indicates that a metabolic defect in these monocytes, which permits the overproduction of cytokines, may be responsible for disease pathogenesis. The metabolic defect can result from genetic defects.

IL6 is a multifunctional cytokine with a critical role in host defense, and has important features like stimulating the hepatic acute phase response to infection and injury. IL6 can be rapidly cleared from the plasma, so circulating levels of IL6 are largely regulated by its expression (10). A C/G polymorphism of IL 6 has been related to different IL 6 serum plasma values and transcription rates of IL 6 gene among healthy individuals $(10,14)$. Furthermore, plasma IL 6 values were increased in NASH patients in a pilot study (6). In our study, the role of IL 6 polymorphism in the "second hit" pathophysiology of NASH was examined, but no statistically remarkable difference was found between NASH patients and healthy controls. Some studies concluded that IL6 polymorphisms affect histopathological progression of $\mathrm{HCV}$, hepatic insulin resistance, inflammation and occurrence and development of HCC $(12,13,25-27)$.

In our study, among NASH patients, there was not a difference between the fibrosis groups regarding IL6 and IL8 gene polymorphisms. NASH may progress to liver fibrosis, liver failure and eventually death. However, not all individuals exposed to a similar causal agent develop the same degree of liver fibrosis. Besides, there is very little 
information about factors affecting fibrosis development in NASH (28). While some studies showed that HFE C282Y heterozygosity and PNPLA3 gene are associated with faster fibrosis advancement, the others have not concluded these outcomes $(15,29)$. Besides, the impact of interracial differences on the pathophysiology of this common disease should be investigated. In conclusion, we showed that IL6 and IL8 gene polymorphisms had no effect on NASH pathogenesis and progression of liver fibrosis; however, the presence of A/A genotype in IL 8 gene is associated with disease progression. Genetic factors influencing the progression of liver fibrosis among NASH patients need further investigation in different racial populations.

\section{Authors' Contributions}

Conception and design, literature search, statistical analysis, writing and critical revision of the manuscript: Mustafa Cengiz. Conception, data interpretation and critical revision of the manuscript: Demet Gökalp Yasar and Seren Ozenirler. Genetic analysis, data interpretation and critical revision of the manuscript: Mehmet Ali Ergün. Histopathological evaluation and scientifically revision of the manuscript: Gulen Akyol.

\section{References}

1. Vernon G, Baranova A, Younossi ZM. Systematic review: the epidemiology and natural history of non-alcoholic fatty liver disease and non-alcoholic steatohepatitis in adults. Aliment Pharmacol Ther. 2011;34(3):274-85.

2. Day CP, James OF. Steatohepatitis: a tale of two "hits"? Gastroenterology. 1998;114(4):842-5.

3. Sanyal AJ. AGA technical review on nonalcoholic fatty liver disease. Gastroenterology. 2002;123(5):1705-25.

4. Harada A, Sekido N, Akahoshi T, Wada T, Mukaida N, Matsushima K. Essential involvement of interleukin-8 (IL-8) in acute inflammation. J Leukoc Biol.1994;56(5):559-64.

5. Bahcecioglu IH, Yalniz M, Ataseven H, Ilhan N, Ozercan IH, Seckin $\mathrm{D}$, et al. Levels of serum hyaluronic acid, TNF-alpha and IL-8 in patients with nonalcoholic steatohepatitis. Hepatogastroenterology. 2005;52(65):1549-53.

6. Kugelmas M, Hill DB, Vivian B, Marsano L, McClain CJ. Cytokines and NASH: a pilot study of the effects of lifestyle modification and vitamin E. Hepatology. 2003;38(2):413-9.

7. Torer N, Ozenirler S, Yucel A, Bukan N, Erdem O. Importance of cytokines, oxidative stress and expression of BCL-2 in the pathogenesis of non-alcoholic steatohepatitis. Scand J Gastroenterol. 2007;42(9):1095-101.

8. Vairaktaris E, Yapijakis C, Serefoglou Z, Derka S, Vassiliou S, Nkenke E, et al. The interleukin-8 (-251A/T) polymorphism is associated with increased risk for oral squamous cell carcinoma. Eur J Surg Oncol.2007;33(4):504-7.

9. Heinrich PC, Behrmann I, Haan S, Hermanns HM, Muller-Newen G, Schaper F. Principles of interleukin (IL)-6-type cytokine signalling and its regulation. Biochem J. 2003;374(Pt 1):1-20.

10. Terry CF, Loukaci V, Green FR. Cooperative influence of genetic polymorphisms on interleukin 6 transcriptional regulation. $J$ Biol Chem. 2000;275(24):18138-44.

11. Franceschi C, Olivieri F, Marchegiani F, Cardelli M, Cavallone L, Capri $\mathrm{M}$, et al. Genes involved in immune response/inflamma- tion, IGF1/insulin pathway and response to oxidative stress play a major role in the genetics of human longevity: the lesson of centenarians. Mech Ageing Dev. 2005;126(2):351-61.

12. Nakagawa H, Maeda S, Yoshida H, Tateishi R, Masuzaki R, Ohki T, et al. Serum IL-6 levels and the risk for hepatocarcinogenesis in chronic hepatitis $\mathrm{C}$ patients: an analysis based on gender differences. Int J Cancer. 2009;125(10):2264-9.

13. Wong VW, Yu J, Cheng AS, Wong GL, Chan HY, Chu ES, et al. High serum interleukin-6 level predicts future hepatocellular carcinoma development in patients with chronic hepatitis B. Int J Cancer. 2009;124(12):2766-70.

14. Fishman D, Faulds G, Jeffery R, Mohamed-Ali V, Yudkin JS, Humphries $S$, et al. The effect of novel polymorphisms in the interleukin-6 (IL-6) gene on IL-6 transcription and plasma IL-6 levels, and an association with systemic-onset juvenile chronic arthritis. J Clin Invest. 1998;102(7):1369-76.

15. Bataller R, North KE, Brenner DA. Genetic polymorphisms and the progression of liver fibrosis: a critical appraisal. Hepatology. 2003;37(3):493-503.

16. Wilfred de Alwis NM, Day CP. Genetics of alcoholic liver disease and nonalcoholic fatty liver disease. Semin Liver Dis. 2007;27(1):44-54.

17. Namikawa C, Shu-Ping Z, Vyselaar JR, Nozaki Y, Nemoto Y, Ono M, et al. Polymorphisms of microsomal triglyceride transfer protein gene and manganese superoxide dismutase gene in nonalcoholic steatohepatitis. J Hepatol. 2004;40(5):781-6.

18. Dixon JB, Bhathal PS, Jonsson JR, Dixon AF, Powell EE, O'Brien PE. Pro-fibrotic polymorphisms predictive of advanced liver fibrosis in the severely obese. J Hepatol. 2003;39(6):967-71.

19. Nozaki Y, Saibara T, Nemoto Y, Ono M, Akisawa N, Iwasaki S, et al. Polymorphisms of interleukin-1 beta and beta 3-adrenergic receptor in Japanese patients with nonalcoholic steatohepatitis. Alcohol Clin Exp Res. 2004;28(8 Suppl Proceedings):106S-10S.

20. Brunt EM, Janney CG, Di Bisceglie AM, Neuschwander-Tetri BA, Bacon BR. Nonalcoholic steatohepatitis: a proposal for grading and staging the histological lesions. Am J Gastroenterol. 1999;94(9):2467-74.

21. Kleiner DE, Brunt EM, Van Natta M, Behling C, Contos MJ, Cummings OW, et al. Design and validation of a histological scoring system for nonalcoholic fatty liver disease. Hepatology. 2005;41(6):1313-21.

22. Verma S, Jensen D, Hart J, Mohanty SR. Predictive value of ALT levels for non-alcoholic steatohepatitis (NASH) and advanced fibrosis in non-alcoholic fatty liver disease (NAFLD). Liver Int. 2013;33(9):1398-405.

23. Merriman RB, Aouizerat BE, Bass NM. Genetic influences in nonalcoholic fatty liver disease. J Clin Gastroenterol. 2006;40 Suppl 1:S30-3.

24. Chu CJ, Lu RH, Wang SS, Chang FY, Lin SY, Yang CY, et al. Plasma levels of interleukin-6 and interleukin- 8 in Chinese patients with non-alcoholic fatty liver disease. Hepatogastroenterology. 2007;54(79):2045-8.

25. Falleti E, Fabris C, Vandelli C, Colletta C, Cussigh A, Smirne C, et al. Genetic polymorphisms of interleukin- 6 modulate fibrosis progression in mild chronic hepatitis C. Hum Immunol. 2010;71(10):999-1004

26. Matthews VB, Allen TL, Risis S, Chan MH, Henstridge DC, Watson N, et al. Interleukin-6-deficient mice develop hepatic inflammation and systemic insulin resistance. Diabetologia. 2010;53(11):2431-41.

27. Liu S, Qiu XQ, Zeng XY, Bai H, Bei CH, Yang Y. [Relationship between IL6 -572G/C polymorphism and hepatocellular carcinoma in men]. Zhonghua Gan Zang Bing Za Zhi. 2012;20(6):463-7.

28. Day CP. Non-alcoholic steatohepatitis (NASH): where are we now and where are we going? Gut. 2002;50(5):585-8.

29. Kawaguchi T, Sumida Y, Umemura A, Matsuo K, Takahashi M Takamura T, et al. Genetic polymorphisms of the human PNPLA3 gene are strongly associated with severity of non-alcoholic fatty liver disease in Japanese. PLoS One. 2012;7(6). 